\title{
Industry sponsored research may report more favourable outcomes
}

\author{
Abstracted from \\ Popelut A, Valet F, Fromentin O, Thomas A, Bouchard P. \\ Relationship between sponsorship and failure rate of dental implants: \\ a systematic approach. PLoS One 2010; 5: e10274. \\ Address for correspondence: Philippe Bouchard, Department of Periodontology, \\ Service of Odontology, Hôtel-Dieu Hospital, AP-HP, Paris 7 - Denis Diderot University, \\ UFR of Odontology, Paris, France. E-mail: phbouch@noos.fr
}

\section{Question: Are scientific articles which are exclusively or partially funded by implants companies more likely to report lower annual implant failure rates compared to articles with non-industry associated sponsorship?}

Data sources Medline and the Cochrane Database of systematic reviews between January 1993 and December 2008. Hand search of 12 different dental journals (Journal of Periodontology, International Dental Journal, British Dental Journal, Journal of the International Academy of Periodontology, Journal Canadian Dental Association, Swedish Dental Journal, Quintessence International, Journal of Clinical Periodontology, Periodontology 2000, Clinical Oral Implant Research, International Journal of Oral and Maxillofacial Implants, International Journal of Prosthodontic, Journal of Prosthetic Dentistry). Language restricted to English.

Study selection Primary articles from systematic reviews that specifically studied the length of survival of dental implants.

Data extraction and synthesis Primary studies were extracted from reviews for which the following information was available: the failure rate of dental implants, publication year, journal Impact Factor, prosthetic design periodontal status, number of dental implants included in the study, methodological quality of studies, presence of a statistical advisor and financial sponsorship. Univariant quasi-Poisson regression and multivariate analysis were used to identity variables that were significantly associated with failure rates.

Results Two independent reviewers identified five systematic reviews from which 41 analysable trials were extracted (Kappa 0.90; 95\% Cl 0.77 - 1.00). The mean annual failure rate estimate for all trials was $1.09 \%(95 \% \mathrm{Cl} 0.84-1.42)$. The mean annual failure rate estimate of non-industry funded trials was $2.74 \%(95 \% \mathrm{Cl} 1.14-6.55)$. Four trials (10\%) reported non-industry funding sources. The funding source was not reported in 26 trials (63\%). 27 trials (66\%) were considered to have a risk of bias. Given study age, both industry associated $(\mathrm{OR}=0.21$; $95 \% \mathrm{Cl} 0.12-0.38)$ and unknown funding sources trials $(\mathrm{OR}=0.33$; $95 \% \mathrm{Cl} 0.21-0.51$ ) had a lower annual failure rate compared with non-industry associated trials. A conflict of interest statement was provided in 2 trials (5\%).

Conclusions After controlling for other factors, the probability of annual implant failure reported in industry associated trials is significantly lower compared with non-industry associated trials. This bias may have significant impact on tooth extraction decision making, research on tooth preservation and government health care policies.

\section{Commentary}

Industry sponsorship in research covers a spectrum of activities. ${ }^{1}$ At one end of this spectrum, the commercial company has complete control over the design, execution, analysis and dissemination of the results and interpretation of a study. At the other end, an independent researcher conceives and completes a study, and then seeks support from industry in the form of financial funding or perks (e.g. free product, trips, etc). In these cases, there is potential for conflict of interest leading to a situation where only results which serve the sponsor's interest will be circulated. ${ }^{1,2}$

Therefore, if research for any discipline of science - including the science of clinical dentistry - is sponsored predominantly by industry, a publication bias favourable to the interest of the industry that sponsored it will ensue.

The commercialisation of oral healthcare by companies promoting their product or services to clinical dentists is evident at trade shows, in trade journals and sponsored Continuing Education (CE) courses. Often, companies will defend claims of superiority and net patient benefit with published research. Potential conflict of interest suggests caution when considering the results of this research, and indeed Prouts et al. confirm these suspicions and quantify the effect. Specifically, industry sponsored research is between $3(\mathrm{OR}=0.33)$ to $5(\mathrm{OR}=0.21)$ times more likely to report industry favourable results than non-industry funded research.

Prouts et al. used dental implants as a model to investigate the effect of industry sponsored research vs. non-industry sponsored research. Only primary studies from a systematic review of systematic reviews were included, thus eliminating many primary studies that have since been published. Although not exhaustive, I find the authors' reason for limiting the review to primary studies from published systematic reviews to be defendable. Systematic reviews are considered the 'cornerstone of medical decision making' because the primary studies cited have undergone a rigorous appraisal process. If current primary studies were included in the review, then it is possible that the estimated effect may be higher as one recent non-industry sponsored article appears to show.$^{3}$

The main focus of authors' analysis is the annual implant failure rate. The authors rigorously analysed the factors that may have had an impact on the primary outcome including: publication year, journal's Impact Factor, prosthetic design, periodontal status, number of dental implants included in the study, methodological quality of studies, presence of a statistical advisor and financial sponsorship. The analysis only included implant supported single tooth and fixed partial edentulous bridges. The quality of the articles analysed 
was assessed according to the following three criteria: 1- inclusion/ exclusion criteria clearly stated, 2- blinding of the examiner and 3- accounted for drop-out rates. Funding sources were identified as industry, industry associated, non-industry and unknown.

Regression analysis shows that both prosthetic design and the source of funding have statistically significant effects on the reported annual failure rates in the reviewed articles. Controlling for publication age and other factors, industry associated trials, as well as trials where the sponsorship was unknown, were more likely to report lower annual failure rates with ORs of 0.21 (95\%CI 0.12 $0.38)$ and 0.33 (95\%CI $0.21-0.51)$ respectively.

Furthermore, the authors assessed that $2 / 3$ rds of the 41 primary studies included in this analysis were prone to bias because they did not clearly describe the inclusion/exclusion criteria, did not adequately blind the examiners and did not appropriately take into account drop-out rates. Furthermore, 73\% of the trials analysed did not identify a statistician, thus making these studies 'questionable'. Only two articles disclosed any conflict of interest.

The mean annual implant failure rate of all 41 studies was found to be $1.09 \%$ (95\%CI $0.84-1.42)$. However the mean annual implant failure rate of the four non-industry sponsored articles was $2.74 \%$ (95\%CI 1.14 - 6.55). Although not statistically significant - possibly a type II error due to the small number of non-industry articles in this analysis - industry sponsored research appears to demonstrate an annual implant failure rate of close to a third of that reported by non-industry sponsored research.

Considering the remarkably low failure rate of implants in either case, I am not prepared to change my clinical practice. I will continue to recommend dental implants as a viable alternative when replacing missing teeth. However, it does sensitise me to the impact industry sponsored research may have on the outcomes in other areas of dental practice: restorative dentistry, oral radiology, oral surgery, prosthetics and periodontics, to name a few. For example, a recent article in the New York Times reported on the potential negative impact of sponsorship bias in the promotion by industry paid clinicians and researchers of cone-beam CT scanners. ${ }^{4}$

This study shows a strong need for more transparency in the sponsorship and declaration of any conflict of interest in all disciplines of dental research.

\section{Practice point}

- There is now evidence to suggest that dental industry sponsored research is more likely to report more favourable outcomes than research from non-industry sponsored research.

\section{Ben Balevi}

Private practitioner, affiliated with Faculty of Medicine, University of British Columbia, Vancouver, British Columbia, Canada

1. Doucet M, Sismondo S. Evaluating solutions to sponsorship bias. / Med Ethics 2008; 34: 627-630.

2. Richards D. 'Nullius in verba'. Evid Based Dent 2010; 11: 66

3. Simonis $P$, Dufour $T$, Tenenbaum H. Long-term implant survival and success: a 10-16-year follow-up of non-submerged dental implants. Clin Oral Implants Res 2010; 21: 772-777.

4. Bogdanish W, McGinty J. Radiation worries for children in dentists' chairs, New York Times, 2010 Nov 22

Evidence-Based Dentistry (2011) 12, 5-6. doi:10.1038/sj.ebd.6400769 